\title{
Enhancing Self-efficacy of Elementary School Students to Learn Mathematics
}

\author{
Sara $\mathrm{Katz}^{1, *}$ \\ ${ }^{1}$ Head of the Research Dept. and English for Academic Purposes Coordinator, Sha'anan Academic College, Haifa, \\ Israel \\ *Correspondence: Sha'anan Academic College, 7 Hayam Hatichon St. Kiriyat Shmuel, P.O.B. 906, Haifa 2640007, \\ Israel. Tel: 972-4-878-0000. E-mail: sara10@012.net.il
}

Received: December 10, 2014

Accepted: January 4, 2015 Online Published: January 23, 2015

doi:10.5430/jct.v4n1p42

URL: http://dx.doi.org/10.5430/jct.v4n1p42

\begin{abstract}
Mathematics is a key to all scientific subjects. Learning mathematics requires cognitive and meta-cognitive effort. Many students suffer from mathematics anxiety that very often leads to physiological symptoms. Self-efficacy is defined as people's beliefs about their capabilities to produce designated levels of performance that affect their lives. Regardless of previous ability achievement, high-efficacious students work harder, persist longer, persevere in the face of adversity, have lower anxiety, and achieve more than low-efficacious students. Therefore, very important in mathematical education is the nurturing of young people who will exercise control over learning mathematics. In this qualitative action research, we diagnosed and attempted to enhance eight $6^{\text {th }}$ graders' efficacy beliefs to learn mathematics. Research tools were 22 interviews, six observations, and 10 field notes. We asked what constituted students' self-efficacy profile to learn mathematics. The constant comparative and grounded theory techniques were used for data analysis. Intervention included goal-setting, skill and strategy acquisition, and reflection. The theoretical contribution of this study is a very detailed diagnosis of self-efficacy resulting in a profile rather than in a single score. Practically, this profile enabled efficient intervention that resulted in students' high self-efficacy and achievement and improvement in teacher instruction.
\end{abstract}

Keywords: qualitative inquiry; self-efficacy; self-regulation; mathematics anxiety; task-value; emotions

\section{Introduction}

The special combination of everyday life activities with high order thinking activities, which characterizes mathematics makes it a key to all scientific subjects, one of the basic milestones of human thinking and scientific technological production. Mathematics as a way of thinking, a language of symbols, terms, definitions and principles, does not develop naturally like a mother tongue, but must be learned, and demands cognitive and meta-cognitive effort. It is built logically in the form of layers, where each stage can be understood only after understanding the previous stage, e.g., without understanding division, one cannot understand fractions. Many students suffer from mathematics anxiety that very often leads to physiological symptoms. To learn mathematics, students have to sense its logics. The teacher's role is to make the learners believe that they are capable of finding the mathematical logics. When teachers' expectations from students are high, the students' efficacy beliefs will be enhanced (Tait-McCutcheon, 2008).

In this qualitative action research, we tried to diagnose and enhance the self-efficacy of $6^{\text {th }}$ graders to learn mathematics. In this chapter, we will address the following issues: beliefs of self-efficacy constitute a key factor of achievement; effects of self-efficacy on the process of learning and on self-regulation; self-efficacy appraisal; children calibration self-efficacy; possible sources of children's low efficacy beliefs to learn mathematics, and attempts to overcome mathematical difficulties.

\subsection{Beliefs of Personal Efficacy Constitute a Key Factor of Achievement}

Self-efficacy is defined as people's beliefs about their capabilities to produce designated levels of performance that exercise influence over events that affect their lives. Self-efficacy beliefs determine how people feel, think, motivate 
themselves, and behave through four major processes: the cognitive, motivational, affective, and selection processes (Bandura, 1997). Self-efficacy has been the focus of research in diverse areas. It has been especially prominent in educational research, where scholars have reported that, regardless of previous achievement of ability, high-efficacious students work harder, persist longer, persevere in the face of adversity, have greater optimism and lower anxiety, and achieve more than low-efficacious students. They approach difficult tasks as challenges to be mastered rather than as threats to be avoided. Such students set themselves challenging goals and maintain strong commitment to them. They use more cognitive and meta-cognitive strategies, and achieve more than those who do not have strong beliefs (Pintrich, \& DeGroot, 1990). An efficacious outlook reduces stress and lowers vulnerability to depression. In contrast, students who doubt their capabilities shy away from difficult tasks, which they view as personal threats. They have low aspirations and weak commitment to the goals they choose to pursue. When faced with difficult tasks, they dwell on their personal deficiencies and on the obstacles they will encounter, rather than concentrating on how to perform successfully. They give up quickly in the face of difficulties, and are slow to recover their sense of efficacy following failure. They lose faith in their capabilities very quickly and fall easy victim to stress and depression (Maier, \& Curtin, 2005). Therefore, very important in mathematics education is to nurture young people who will approach threatening situations in learning mathematics with the confidence that they can exercise control over them. It is obvious that competent functioning requires harmony between self-beliefs, on the one hand, and possessed skills and knowledge, on the other. However, as people interpret the results of their achievements and judge the quality of their knowledge and skills through these personal beliefs (Pajares, 2005), self-efficacy, thus, operates as a key factor in the generative system of human competence (Bandura, 1997).

\subsection{Effects of SE on the Process of Learning and on Self-Regulation}

Evidence from many meta-analyses of more than two decades of study shows that efficacy beliefs contribute significantly to level of motivation and learning, socio-cognitive functioning, emotional well-being, and performance accomplishments. Therefore, they are crucial for educating young people (Bandura, 2005; Zimmerman, 2000). Self-efficacy has an effect on cognitive and meta-cognitive functioning, such as problem solving, decision making, analytical strategy use, self-evaluation, time management, and self-regulation strategies, all of which affect academic achievement (Bandura, 1997; Bandura, 2005). Efficacy beliefs play an essential role in all phases of self-regulation and achievement (Schunk \& Zimmerman, 2006). Mathematics research shows that self-regulation has an effect on mathematical performance (Fast, Lewis, Bryant, Bocian, \& Cardullo, 2010). When self-regulatory processes play an integral role in the development and use of study skills, students become more acutely aware of improvements in their academic achievement and experience a heightened sense of personal efficacy (Zimmerman, Bonner, \& Kovach, 1996). Efficacy beliefs provide students with a sense of agency to motivate their learning through use of self-regulatory processes such as goal setting, self-monitoring, self-evaluation, and strategy use. The more capable students judge themselves to be, the more challenging the goals they embrace, the better they are at monitoring their working time, at persisting, at solving problems, and at self-evaluating standards they use to judge the outcomes of their self-monitoring. The greater academic self-regulation of self-efficacious students produces higher academic achievements (Zimmerman, 2000).

\subsection{Self-efficacy Appraisal}

According to Bandura (1997), learners obtain information to appraise their self-efficacy from four principal sources: a. Enactive mastery experiences that serve as indicators of capability. Successful outcomes boost self-efficacy whereas failures lower it, b. Vicarious experiences that alter beliefs through transmission of competencies and comparison with the attainments of others, $\mathbf{c}$. Verbal persuasion by others that they possess certain capabilities, and $\mathbf{d}$. Physiological and affective states from which they judge their capableness. Research shows that mastery experiences are significant predictors of self-efficacy (Britner, \& Pajares, 2006). It is through the students' interpretation of their performance that their self-efficacy is developed, resulting in a positive correlation between self-efficacy and achievement (Corkett, Hatt, \& Benevides, 2011). Thus, enactive experiences are the most influential source of efficacy beliefs because they are predicted based on the outcomes of personal experiences, whereas vicarious influences depend on an observer's self-comparison with as well as outcomes attained by a model. Verbal persuasion has an even more limited impact on students' self-efficacy because outcomes are described, not directly witnessed, and thus depend on the credibility of the persuader (Zimmerman, 2000). It is important to note that the four main constructs are not hierarchical and that it is possible for all four constructs to be influencing a student's self-efficacy at the same time (Corkett et al., 2011). Efficacy appraisals are a product of cognitive processing either of one source or of diverse sources of efficacy information. Once formed, they contribute to the quality of human functioning in diverse ways. 
Theorists agree that accuracy of self-efficacy appraisals is an important issue, as unreal appraisals deter students from learning (Schunk \& Zimmerman, 2006). Lately, more attention has been paid to the issue of calibration of students' efficacy beliefs in relation to their actual performance.

\subsection{Children Calibration Self-Efficacy}

The difference between efficacy beliefs and actual performance generates five types of self-efficacious atudents, which must be taken into account when teaching mathematics (Bandura, 1997; Klassen, 2002).

The first is the realistic type of students, whose efficacy appraisals correspond to their performance level. Under cautious realistic self-appraisals, these students rarely set aspirations beyond their immediate reach, nor do they mount the extra effort needed to surpass their ordinary performances (Bandura, 1997).

The second and third types are the unrealistically low or high efficacious learner types whose beliefs are exaggeratedly lower or higher than their actual performance. Both types act on faulty self-efficacy judgments and might suffer adverse consequences. Researchers have found that unrealistic appraisals are common and that over-confidence is a frequent problem (Pajares \& Graham, 1999; Zimmerman, 1995).

The fourth is the optimistic type, whose efficacy beliefs are slightly higher than their performance. This difference is the best according to Bandura (1997), in that it enables individuals to use their talents to reach their maximum potential by raising aspirations and sustaining motivation.

The fifth is an anxious type whose beliefs are slightly lower than their performance. Evidence was found showing that efficacy appraisals that are slightly lower than performance might result in high performance, because these people seek perfection and are worried that they do not know enough (Katz, 2013). Inaccurate estimates of self-efficacy might develop from faulty task analysis or from lack of self-knowledge (Bandura, 1997), which are two problems shown to be prevalent in students in schools.

\subsection{Possible Sources of Children Low Efficacy-Beliefs to Learn Mathematics}

As children get older and understand themselves better, they become progressively more accurate and improve their self-appraisal skills. Many children are severely handicapped by disbelief in their efficacy stemming from faulty self-appraisal especially in learning mathematics. They have much to gain from changing a negatively biased system of self-appraisal into a more accurate one. Students with unrealistically high self-efficacy act on faulty efficacy judgments, which deter them from learning properly. Students with unrealistically low self-efficacy will not undertake challenges. It is important for teachers to focus on young students' self-efficacy because once self-efficacy is established it can be resistant to change (Hoy \& Spero, 2005).

Mathematics is a hierarchical discipline built of stages that depend on one another. Construction of a new stage requires the learner to have learned and experienced the previous one. Skipping one stage or teaching two steps together may cause misunderstanding resulting in stress or anxiety. This emotional reaction sustains the student's ability to think when coping with mathematical problems. This irrational fear may cause helplessness and lack of mental organization ability (Ashcraft, \& Krause, 2007). An interesting result shows that $17 \%$ of the entire population suffers from high mathematical anxiety (Berch, \& Mazzocco, 2007). Another possible reason for mathematical anxiety might be teachers' lack of consideration for the learner's needs; teacher's lack of consideration for the student's learning styles, and/or lack of authenticity in teaching and lack of appropriate environments (Berch, \& Mazzocco, 2007).

When students produce wrong answers, it shows a lack of understanding of the material, which therefore needs repeating. There is an assumption that students who tend to give wrong answers are probably less competent than others in mathematics. Students usually compare their grades to those of other students and students who are labeled less competent expect to find future mathematical tasks difficult. As they advance through school, they meet other teachers and if continually labeled as weak, they accept the status quo and are either unable or unwilling to change it.

Longitudinal investigations on students who had experienced difficulties in mathematics, without taking into account motivation and previous mathematical knowledge, found that they had problems in slow or imprecise drawing out of working memory of simple basic mathematical principles that deter them from logically following the teacher's explanations. Teachers and text-book authors usually assume that most students easily draw out these basic mathematical principles, and therefore base teaching on this misleading assumption. The students who lack arithmetic knowledge think that they will never be able to succeed in mathematics. Unfortunately, their teachers are led by this misconception, thus predetermining the failure of these students (Geary, 2004). Concentration difficulties deter many students from focusing on a given task; others have difficulty creating mental models of mathematical 
terms or understanding mathematical symbols. Others have difficulty retaining information in their working memory (Krasanti, \& Harkavi, 2003). Over the years, investigators have learned to elicit positive innate abilities of students with mathematical difficulties.

\subsection{Attempts to Overcome Mathematical Difficulties}

Investigators have found that raising students' trust in their teachers, enhancing self-beliefs, as well as improving teaching styles and using interesting activities in the classroom might reveal and empower these students' abilities, thus enhancing their achievement in mathematics. Researchers have planned interventions that helped students overcome their mathematics learning difficulties. They made a slow, gradual transfer from visual presentations to symbols, through techniques that use visual organizers and instruments, such as calculators, to overcome arithmetic problems. They used clear and systematic strategy teaching, verbalizing thoughts through talking, writing, drawing the steps they took to solve mathematical problems; they used interventions that took care of students' impulsiveness, thinking aloud and peer assessment (Chazan, 2000). These attempts are helpful but many students are still intimidated by mathematics. Our attempt focuses on the very beginning of the diagnostic step of students' beliefs about their mathematical functioning, where the source of their problems lies.

The aim of this study was to diagnose the efficacy beliefs of $6^{\text {th }}$ graders who experienced difficulties in learning mathematics, to enhance their beliefs, their achievements, and their teacher's professional development.

The questions we asked were as follows:

1. How was the students' self-efficacy to learn mathematics pre-intervention?

2. How did they feel about mathematics pre-intervention?

3. What kind of past experiences had they had?

4. How was the students' self-efficacy post-intervention?

5. How did they feel about mathematics post-intervention?

6. What kind of experiences did they have during the intervention period?

\section{Methods}

\subsection{Participants}

Participants were eight average 12-year-old learners in a $6^{\text {th }}$ grade class that contained 29 students. These students experienced difficulties in learning mathematics. They either hated or were worried about mathematics.

\subsection{Design and Procedure}

This was a qualitative action research designed to elicit tacit knowledge on self-efficacy beliefs of students to learn mathematics, to analyze it, to describe it, and to diagnose problems in order to solve them. In this case study we used qualitative tools and methodology. It consisted of systematic, yet flexible, guidelines for collecting and analyzing data to construct abstractions. The flexibility and openness of the qualitative approach enabled revelation of tacit knowledge (Stake, 2010).

Students were asked about their past experiences, how they felt about their friends, about their feelings, and about how much support they received from others when learning mathematics. Listening, observing, communicating and remaining in the field of the study for a prolonged period allowed the teacher/researcher, first, to understand and create a picture of the participants' reality in her mind, and second, to reflect deeply on her professional work as a producer and enhancer of knowledge.

All parents gave written informed consent to their children's participation. They understood that the study was meant to enhance their children's achievements in mathematics. Privacy was protected and code numbers were used. The participants and parents were allowed to read the results of the analysis, if they so wished.

\subsection{Research Tools}

Three research tools were used in this study; these included: Open interviews, open observations, and field notes taken pre- and post-intervention. Eight pre-intervention interviews were conducted with each student and three with parents. The same number was conducted post-intervention. During the interviews, the participants were asked to talk about themselves during mathematics lessons, while learning at home, doing homework, and about anything else related. Informative and elaborative questions were used and the atmosphere was relaxed. Communication was 
pleasant and the students' facial expressions were supportive to the interviewer. Three observations were conducted pre- and post-intervention, each lasting 45 minutes. The researcher took 10 field notes regarding the students' behavior and comments both during and post interactions.

Intervention tools were: goal setting including reinforcement; skill and strategy acquisition, and open reflection tasks on their self-efficacy to learn mathematics. A table was used for goal setting. After a consultation with the teacher, the student decided on a daily goal, which, when accomplished, was marked by a "v" in the table. For example: "I will answer one question in class every day." Once one goal was accomplished, another goal was added, hence creating a gradual accumulation. The table was a type of contract between the teacher and the student. The student progressed from a daily goal to a weekly goal, then set a goal for a month, and finally, for three months. In the one-on-one meetings with the teacher, the student thought aloud and reflected orally on his/her accomplishments, self-evaluation, conclusion drawing, self-judgment of success, and setting of a new goal, which was added to the list. The meetings included the teacher's reinforcements.

The second tool was acquiring mathematical skills and strategies to learn simple fractions, decimal numbers, percentages, verbal problems, perimeters and areas, volume and angles in geometry. The skills and strategies were taught gradually, in challenging ways, while reinforcing the students. The teacher tried to create as many experiences of success as possible, to increase the students' beliefs in their abilities.

To activate self-regulation thinking processes, students were asked to write 20 open, unstructured reflection tasks during the academic year, in which they described their thoughts, attitudes, and emotions on learning mathematics. They were free to write whenever they wanted.

\subsection{Data Analysis}

The qualitative methodological frame used for analysis was criteria oriented methodology, which assumes that open analyses are often influenced by perspectives and views held by the researchers (Guba \& Lincoln, 2005). Charmaz (2006) argues that preconceived theoretical concepts may provide starting points for looking at the data but they do not offer automatic codes for analyzing these data (Charmaz, 2006). Of all qualitative frames, this one is the closest to quantitative methodology.

Constant comparative analysis (Stake, 2010) and grounded theory techniques (Glaser \& Strauss, 1967) were used to generate the students' efficacy profile to learn mathematics. The unit of analysis was a sentence. The units were coded into categories through three-phase coding: initial, axial and selective coding (Charmaz, 2006). Each unit was compared with other units or with properties of a category. Analyses began during data collection and continued after its conclusion. Recurring themes were examined and gathered under criteria, which were then categorized. Under the restrictive qualitative rules of the constant comparison analysis methodology, core constructs were formed. A core construct is a category which contains dense descriptions of evidence supporting it. The constant comparison of units was adapted, changed, and redesigned as the study proceeded, and resulted in a refined list of categories that were developed into conceptual abstractions called constructs. The concept map was sampled only when repetition of the same constructs was obtained from multiple cases, and when new units did not point to any new aspect, which meant that the list of constructs had reached theoretical saturation (Janesick, 1994). The numbers and percentages of the themes of every construct were calculated and demonstrated by a pie (See the Figures in the Results section).

Qualitative validity of data gathering was obtained when the same categories elicited from one tool emerged from the other tools as well. Qualitative validity of data analysis was checked by comparing the researcher's results with those of an external rater $(n=10)$. Member-checking was performed by obtaining the participants' responses to the researcher's interpretations.

\section{Results}

Data collection included 4321 units of evidence. Emerging results were as follows:

Result 3.1. We wished to obtain a picture of the students' self-efficacy to learn mathematics pre-intervention. Three constructs emerged from this analysis, as illustrated in Figure 1: 


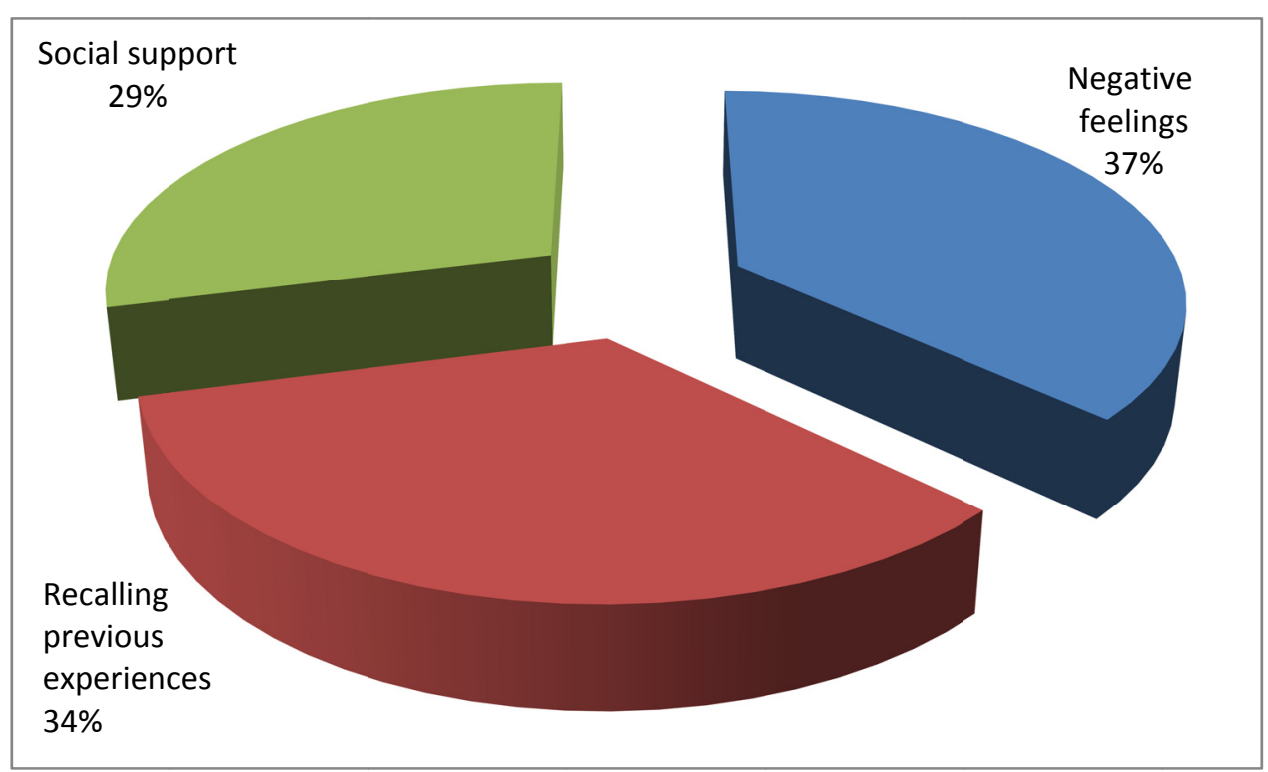

Figure 1. The Students' Pre-Intervention Self-Efficacy Profile to Learn Mathematics

The first construct, containing 37\% of the evidence, showed 'negative feelings' towards learning mathematics.

"I have been afraid of these lessons for as long as I can remember myself." (Interview 2)

The second construct was 'recalling previous experience' (34\%).

The third construct (29\%) described a large amount of 'social support':

"Mom always checks my homework for me." (Interview 1)

Result 3.2. To reveal the students' feelings about mathematics, we performed another analysis of the 'negative feelings' construct as illustrated in Figure 2:

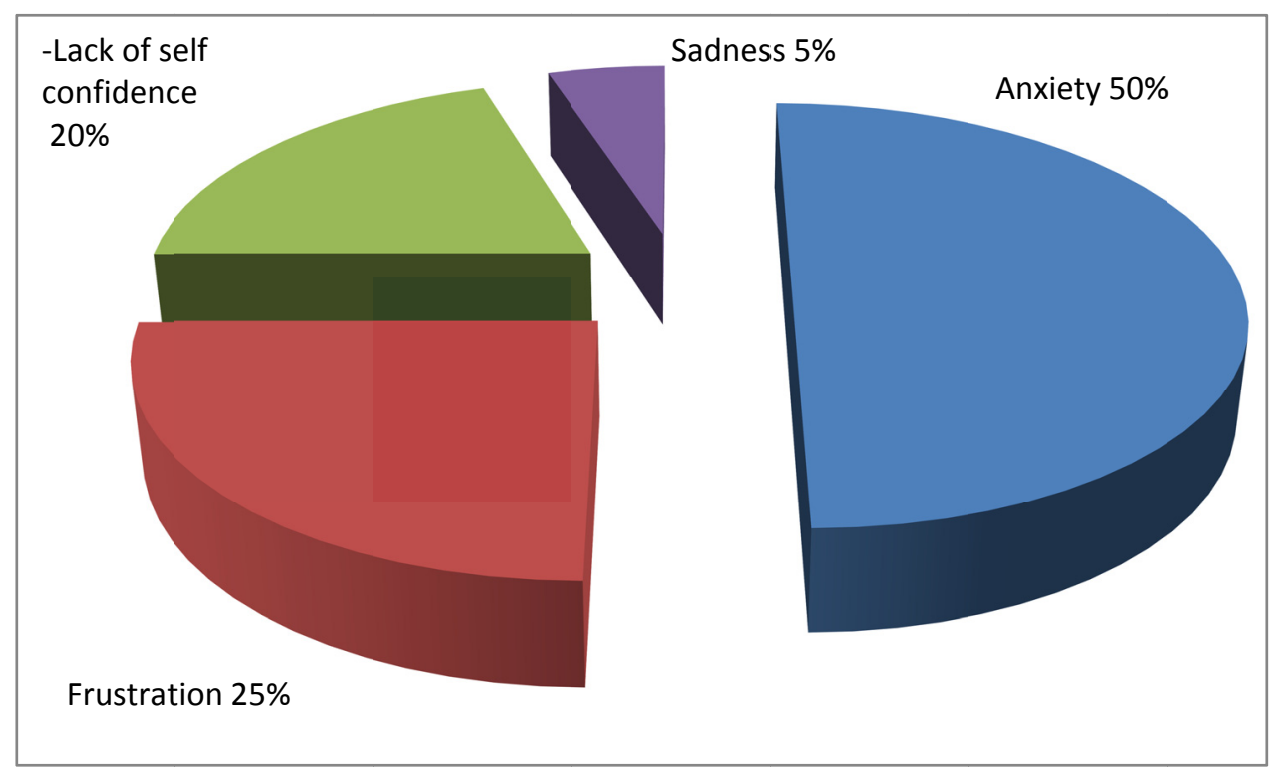

Figure 2. Description of Students' Feelings towards Mathematics Pre-Intervention

Results showed that 'anxiety' was the dominant emotion (50\%):

"I can't fall asleep, I keep tossing and turning in bed, I see only numbers." (Interview 6)

Other results were: 'frustration' (25\%):

"I hate those exercises." (Interview 9),

'lack of self-confidence' (20\%): 
"I'm afraid I'll fail." (Field note),

and 'sadness' (5\%):

"I am sad." (Field note)

Result 3.3. We were curious to know what the 'recalling previous experiences' construct contained. We performed an analysis of this part only, as described in Figure 3:

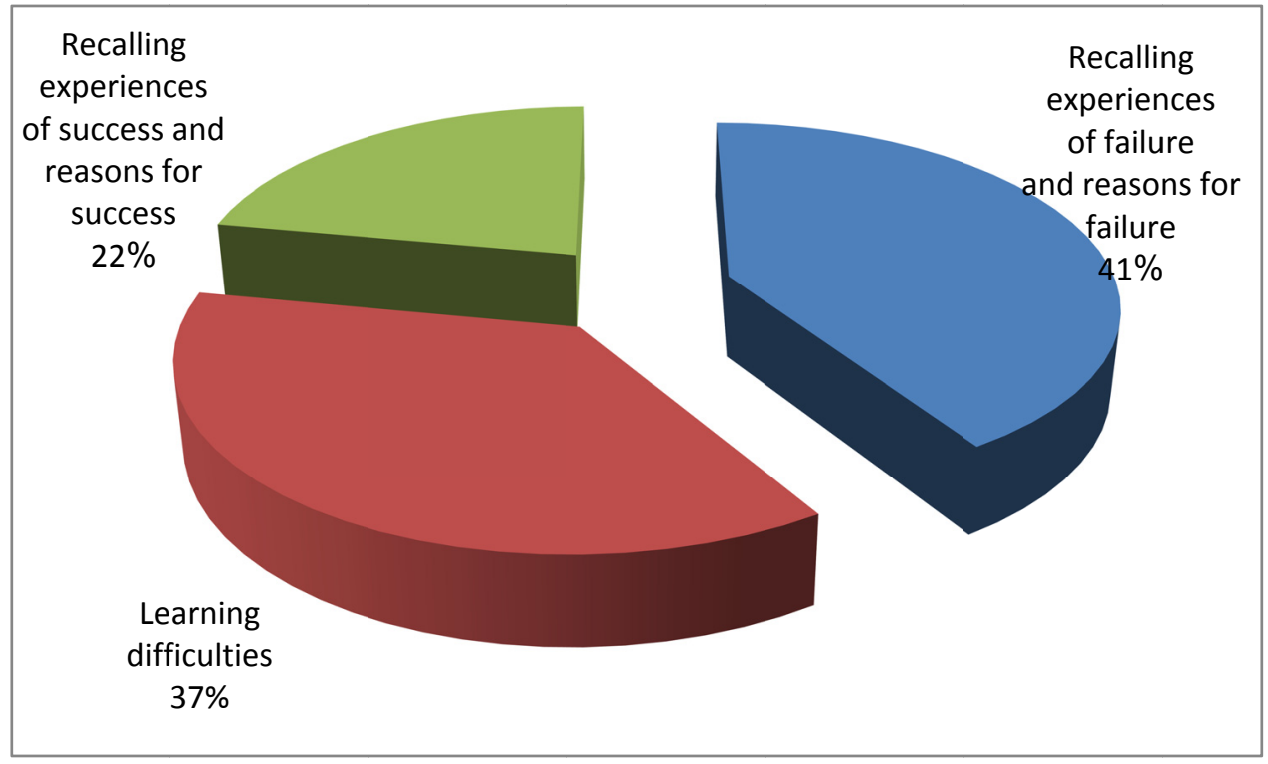

Figure 3. Students' Pre-Intervention Recalling of Previous Experiences of Mathematics

The dominant construct was 'recalling failures and the reasons for failure' (41\%):

"...so that was a failure, I was tired of practicing." (From interview)

The second construct was 'difficulties in mathematics' (37\%), such as misunderstanding and complexity of the material.

The third construct was: 'recalling successes and the reasons for success' (22\%) and attributing them to expending effort. We found that they had more failures and difficulties (78\%) than successes (22\%) in mathematics.

Result 3.4. To answer the question of how the students' self-efficacy to learn mathematics looked post-intervention, we analyzed the data gathered following the intervention. Emerging constructs are illustrated in Figure 4:

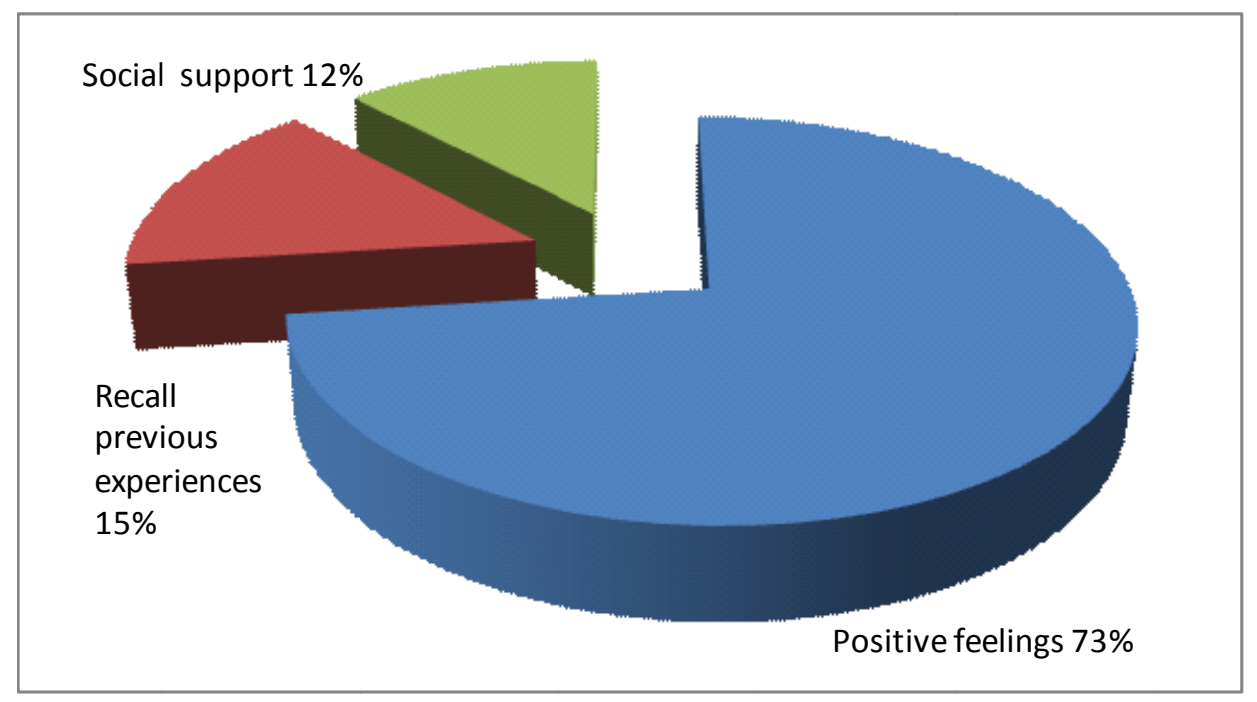

Figure 4. The Students' Post-Intervention Self-Efficacy Profile to Learn Mathematics 
The first emerging construct was 'positive feelings towards mathematics' (73\%).

"My son is happy today, and I'm relaxed." (Interview 1)

The second construct was 'recalling previous experiences' (15\%) where students recalled their experiences during intervention.

"We set a new goal every week and succeeded." (Field notes)

The third (12\%) described the 'social support' of parents, friends, teachers, and others, which was less than the pre-intervention support received by students $(28 \%)$. There was no evidence of difficulties in mathematics post-intervention.

Result 3.5. The additional analysis of the 'positive feelings' construct elicited the following results (Figure 5):

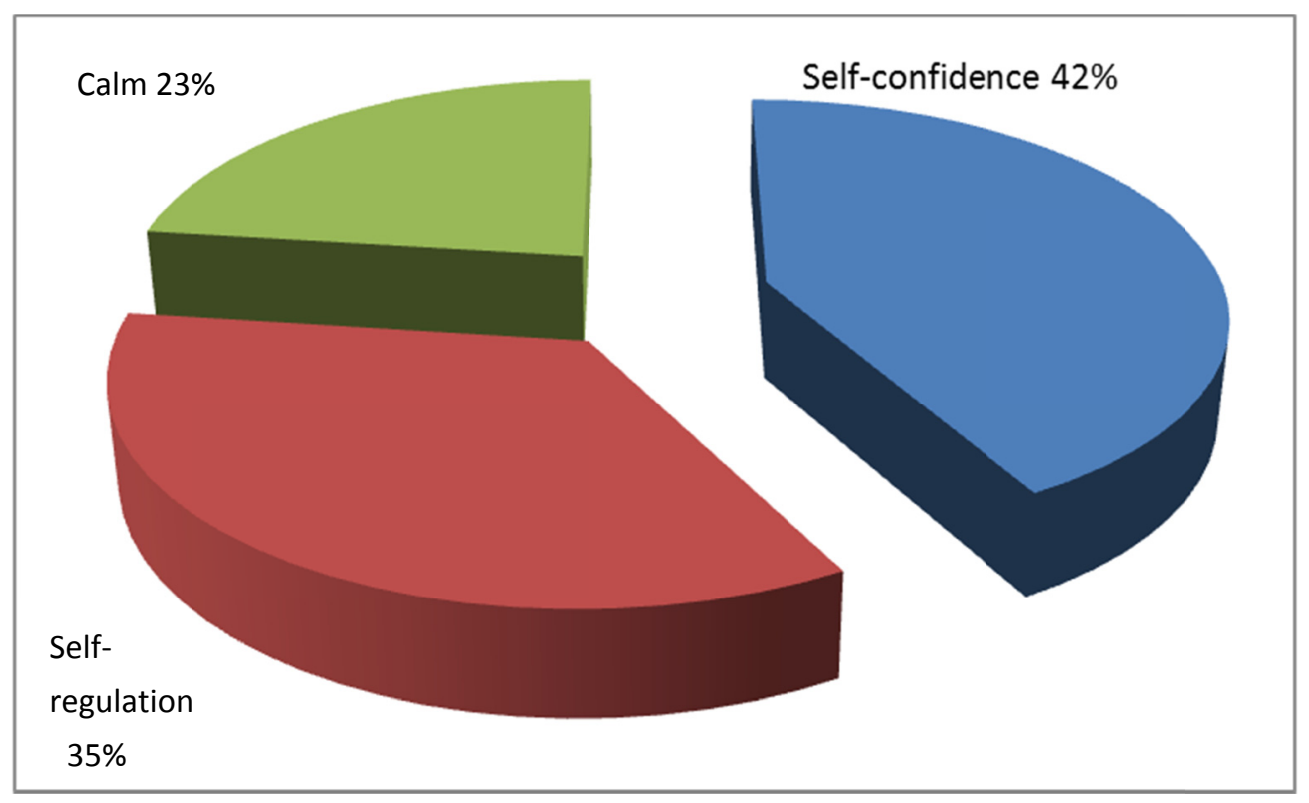

Figure 5. Description of Students' Feelings towards Mathematics Post-Intervention

Following the intervention, students felt 'self-confident' about mathematics (42\%):

"I believe in myself. I can do it!" (Observation 3);

'self-regulated' (35\%):

"I started to work on my math problems alone." (Interview 2), and 'calm' (23\%):

"He is less excited, he smiles during math lessons." (Interview 17)

Result 3.6. To discover the students' types of experiences during and after the intervention period, we analyzed the 'recalling previous experiences' construct and found a very clear distinction between positive and negative experiences and their reasons, as shown in Figure 6: 


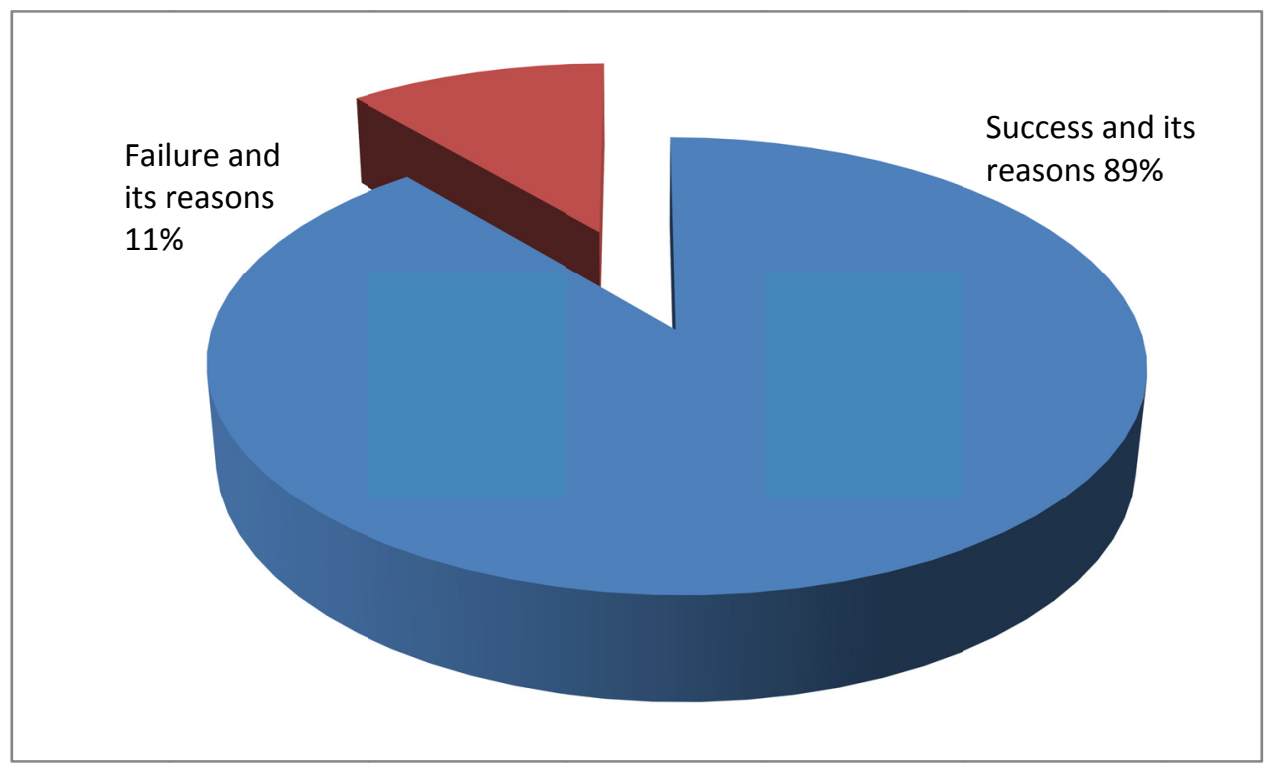

Figure 6. Recalling Previous Experiences in Mathematics Post-Intervention

Two main constructs emerged from this analysis: Participants reflected on their experiences post-intervention, on the reasons for their positive self-efficacy and success in mathematics and the teacher's reinforcement that followed (89\%). They described experiences of failure and the reasons for those failures $(11 \%)$. The main reason for success was the previous experience of success, as experiencing success led to further success. The main reason for failure was stress.

Privacy was protected by using code numbers. A group member-checking session was performed and the participants' response to the researcher's interpretations was obtained. Participants were satisfied with the results.

Data collection was validated; the categories elicited from one tool emerged from the other tools as well. Agreement between the researcher and an external rater on data analysis was $86 \%$.

\section{Discussion}

The purpose of this study was to diagnose the efficacy beliefs of eight $6^{\text {th }}$ graders who experienced difficulties in learning mathematics, to enhance their efficacy beliefs, their achievements, and their teacher's professional development. The purpose of the study was achieved: Post-intervention self-efficacy to learn mathematics was higher and mathematics anxiety was lower than pre-intervention self-efficacy. Self-regulation emerged, achievement was enhanced, and difficulties were not evidenced post-intervention. In this chapter, we will discuss the use of the qualitative methodology and tools for diagnosing efficacy beliefs to learn mathematics; self-efficacy as predictor of performance; the role of successful experiences and reinforcement in enhancing efficacy beliefs; the role of reflection in enhancing self-efficacy processes; teacher instruction, and the combination of skill and strategy acquisition and reflection training.

\subsection{Diagnosing Efficacy Beliefs to Learn Mathematics Qualitatively}

This study suggests a broadening of the methodology for diagnosing self-efficacy to learn mathematics, offering an alternative qualitative way for assessing efficacy beliefs in mathematics. Self-efficacy has been assessed using quantitative questionnaires that ask students to rate their confidence to perform a specific task on a certain level which ends in a score on a scale. Bandura $(1997,2005)$ argued that reasonably precise judgments of capability matched to a specific outcome afford the greatest prediction and offer the best explanation of behavioral outcomes (Bandura, 1997, 2005). To this end, efficacy judgments have been tailored to the task under investigation. We believe that a final score is insufficient for deciding on a problem and its efficient intervention. Students process the information that enters their minds through external and internal comparisons, recollections, evaluations, and judgments of their efficacy beliefs, pre-appraising their self-efficacy. We offered a profound analysis to elicit and diagnose efficacy beliefs in a more detailed, authentic, and precise way than questionnaires. This alternative way of analysis reflects the self-efficacy mechanism as an X-ray analysis that results in a detailed profile of students' 
efficacy beliefs towards mathematics. This macro analytic assessment observes the individual's mechanism of mathematics self-efficacy as a whole, which is not only close to reality, but it is the authentic reality itself. This methodology uses a variety of authentic contexts, offers students a fair chance to present themselves as they wish, and hence this method suits our purpose. The participants responded positively and were willing to supply information on their beliefs, personality, and experiences. The constructs were generated by repeated analyses, and qualitative validity was achieved. The close researcher-participant relationship facilitated the participants' open reflection and cooperation with the researcher, and the attainment of new insights. For tracing problems and tailoring interventions, an open profile of efficacy beliefs is far more effective than a self-efficacy score on a scale.

Three main detailed themes emerged in this diagnosis: The first was 'negative feelings', such as anxiety (50\%), frustration (25\%), low self-confidence (20\%) and sadness (5\%) which were evidenced pre-intervention (Figure 2), and became positive post-intervention, turning into feelings of self-confidence (42\%), self-regulation (35\%), and calm (23\%), (See figure 5): Here is an example:

Pre-intervention:

"Mathematics is a torture, I am always afraid to be asked a question in class. I often cry at night." (Interview 6),

Poat-intervention:

"Today I'm more optimistic and calm." (Interview 14)

Feeling calm rather than worried when preparing for, or performing a task led to high feelings of self-efficacy ( $73 \%$, Figure 4).

The second theme that emerged pre-intervention was 'social support'. It was 29\%, (Figure 1), and was reduced to $12 \%$ post-intervention (Figure 4), when positive feelings emerged (73\%, Figure 4). Those positive feelings included self-confidence and self-regulation (Figure 5). Here is an example:

Pre-intervention:

"I couldn't do it without your help." (Observation)

Post-intervention:

"Mom was surprised when she saw me doing it alone." (Observation)

When students' self-efficacy was low they needed help from parents and teachers. Those beliefs were reduced when self-regulation and self-confidence emerged. Students then became self-efficacious and less dependent on others.

The third theme that emerged was 'recalling previous experiences'. This theme that contained recalling negative experiences of failure and their reasons, and learning difficulties in mathematics (78\%, Figure 3), reflected low self-efficacy pre-intervention:

"She ignores mathematics." (Field notes),

"The paper becomes black when I start mathematics." (Interview 1)

"I can't practice." (Interview 6).

These experiences turned into recalling experiences of success (89\%, Figure 6) post-intervention:

"I put in a lot of effort, besides, I learn with friends." (Interview 7)

Evidence of learning difficulties was not reported by participants post-intervention, as they had positive experiences during intervention and these raised their positive efficacy beliefs to such a degree that they seemed to forget their learning difficulties, which, we assume, did not disappear.

"I started to practice. I started to think that I'm good in math. I feel as if I blocked the block." (Interview 17)

These results support the literature on enactive mastery experiences that serve as the most influential source of efficacy information because they provide the most authentic evidence of whether one can muster whatever it takes to succeed (Bandura, 1997).

The precise descriptions of the student's low self-efficacy enabled conducting initiated experiences of success, goal setting, and skill and reflection training that together enhanced efficacy beliefs of the students in this study. 


\subsection{Self-efficacy as Predictor of Performance}

This study showed that people needed firm beliefs of personal efficacy beliefs to turn concerns into effective actions. The evidence of this study supports placing emphasis on self-efficacy as an important factor in teaching and enhancing success in mathematics, as described by the following student:

"I didn't fail in mathematics; I failed in my feelings, in my attitude."

Low self-efficacy at the beginning of the year resulted in almost no learning and practice, leading to failure, which in turn led to low self-efficacy. When self-efficacy was raised:

"I'm in another place today regarding my attitude to math. There is no way that I will fail." (Observation)

Indeed she did not fail. Performance was better and students did not report difficulties.

We recommend teaching students self-efficacy techniques, such as keeping check lists, rating scales, questionnaires, and diaries, raising efficacy beliefs by supplying successful mastery experiences, and pleasant physiological and affective states that serve as indicators of capability and provide encouraging feedback substantiated by success (Schunk \& Zimmerman, 2007).

If we assign a central role to self-efficacy skills, learners will be motivated to look at their strengths and weaknesses, and gain more accurate appraisals that will generate better attainments (Tedick, 2006).

\subsection{Initiating and Reinforcing Successful Experiences}

Initiating and reinforcing successful experiences using the goal setting tool had didactic and psychological purposes. When the students met with the teacher, they discussed the goals, but it was the student who decided on the goals, and the teacher facilitated the process. The teacher was the guard who made sure that the goals would be challenging, but also gradual and realistic, and not too difficult to accomplish. When the students succeeded, the teacher reinforced their success. Reflective verbalization followed every performance and the accumulated number of goals increased. Students reported that the experiences of success and teacher's reinforcements were the main reason for their better achievements in mathematics (Figure 6). This supports Bandura's theory on mastery experiences as significant predictors of self-efficacy (Britner \& Pajares, 2006).

Children's knowledge of their performance capabilities might be inaccurate. Teachers' feedback at that elementary level was intended to encourage them. Since efficacy beliefs are developed through interpretations of performance outcomes, teachers' role is to maximize the impact of mastery experience by providing feedback and encouragement that help students interpret these experiences in ways that enhance self-efficacy. Students were also encouraged to persist despite difficulties, and when performing their tasks, they were supplied with relaxed environments

\subsection{The Role of Reflection in Enhancing Self-Efficacy Processes and Teacher Instruction}

Result 3.6 shows that reflection was a second reason for the students' enhanced self-efficacy and achievement. Reflection involves awareness at every stage, which serves as a basis for high order thinking process development. Evidence was found showing that meta-cognition has an effect on mathematical performance (Birenbaum \& Nasser, 2003). Students with low self-awareness used intuition and relied on previous appraisals with no use of active deep thinking. Reflection is inner talk, which is the main process of self-regulated learning, where learners communicate with themselves and with their sources of information; it is their evaluation and criticism of the way they explain their world:

"During this time I convinced myself that I have to succeed in that exam; there was a lot of talking to myself. Finally, I made it!"

Habitual reflection on self-efficacy might be used as a tool for nurturing high order thinking processes (Katz, 2013), which mathematical learning demands. The possibility of nurturing self-efficacy appraisals opens new windows to changing biased systems of many students in mathematics.

As an action research, the teacher kept reflecting and thus improved her work, becoming flexible and ready for changes:

"I've changed my teaching style. I use graphic organizers when I explain; I try to understand the student and his needs; I ask experts when I encounter a problem, and more than anything, I succeed in initiating successful experiences that lead them to believe in their capabilities." (Teacher reflection)

"This study gave me a chance to look at reality through a new lens and rebuild my professional perspectives. This procedure was not easy or anticipated in advance." (Teacher reflection) 


\section{Conclusions, Implications for the Future, Contribution}

This study revealed efficacy beliefs of students who experienced fear and frustration regarding mathematics and enabled a focused intervention that enhanced efficacy beliefs and achievement.

The combination of skill and reflection training resulted in meta-cognitive awareness and self-regulated processes. The teacher served as a good facilitator; thinking processes improved; new knowledge was built; and learning mathematics became significant (Schunk \& Zimmerman, 2007). We recommend concurrent performance of reflection and skill training.

Successful functioning in mathematics demands a thinking, autonomous person, who is a self-regulated learner. Among the most important competencies required of such a person are meta-cognitive competencies, such as self-reflection, or self-evaluation, which were reported in the findings (See Figure 5). When students experienced low efficacy, they needed social support (See Figure 1). Social support was reduced when self-regulation appeared. Self-regulation enhances not only students' learning but also their perception of self-efficacy, which in a circular way again, enhances self-regulation (Zimmerman, 2000).

Self-regulation and self-efficacy incorporate the same meta-cognitive competencies. The need to develop these competencies expands the scope of this study and thus creates a challenging enterprise for all teachers of mathematics.

We believe that if self-efficacy appraisals and reflection become an integral part of learning, they will make a great contribution to instructional systems for mathematics. If self-efficacy appraisals and reflection play an essential role in any teacher's program, enabling student-teacher interaction, time investment and creative mental effort, students will be forced to rethink and repeatedly revise their appraisals to achieve self-imposed standards of quality, as was the case in this study. This process will help them become self-regulated learners, which will lead to better performance (Birenbaum \& Nasser, 2003).

During the formative period of children's lives, school functions as the primary setting for cultivation of social validation of cognitive capabilities, which is needed for mathematical learning. It is in school that their knowledge and thinking skills are continually tested, evaluated, and socially compared. When they master their skills, they develop a growing sense of their intellectual efficacy. Therefore, one of the fundamental goals of school is to foster children's efficacy beliefs and self-regulatory capabilities to promote successful mathematics learning (Pajares, 2002; Zeldin \& Pajares, 2000).

Eliciting student self-efficacy profile qualitatively is the theoretical contribution of this study, which practically enhanced students' mathematics achievement and the mathematics teacher's professional work. Eliciting efficacy beliefs qualitatively may represent an innovative approach to the formal measurement of self-efficacy in specific areas, and show promise as a fine diagnosis for mathematics learning. Attempts should continue to be made on eliciting self-efficacy to perform in specific areas in mathematics through qualitative methodology. When many case studies show similar results, qualitative generalizability is enhanced (Bandura, 1997; Stake, 2010).

\section{Acknowledgment}

I would like to thank Shaanan Academic College for funding the editing of this article.

\section{Conflict of interest}

The author declares that there is no conflict of interest regarding the publication of this article.

\section{References}

Ashcraft, M. H., \& Krause, J.A. (2007). Working memory, math performance, and math anxiety. Psychonomic Bulletin \& Review, 14(2), 243-248. http://dx.doi.org/10.3758/BF03194059

Bandura, A. (1997). Self Efficacy: The Exercise of Control. NY: Freeman \& Company.

Bandura, A. (2005). Evolution of social cognitive theory. In K. G. Smith \& M. A. Hitt (Eds.), Great Minds in Management (pp. 9-35). Oxford: Oxford Univ. Press

Berch, D. B., \& Mazzocco, M. M. (2007). Why is math so hard for some children? Baltimore, Maryland: Paul H Brookes Publishing, 343-345 
Birenbaum, M., \& Nasser, F. (2003). Self-efficacy in mathematics and test behavior of Jewish and Arab students and implications to the educational counselor work. Educational Counseling, 12, 68-78.

Britner, SH. L., \& Pajares, F. (2006). Sources of science self-efficacy beliefs of middle school students. Journal of Research in Science Teaching, 43(5), 485-499. http://dx.doi.org/10.1002/tea.20131

Charmaz, K. (2006). Constructing Grounded Theory: A Practical Guide through Qualitative Analysis. London: Thousand Oaks; New Delhi: Sage Publications.

Chazan, D. (2000). Beyond Formulas in Mathematics and Teaching: Dynamics of the High School Algebra Classroom. NY: Teachers College Press.

Corkett, J. K., Hatt, B. E., \& Benevides, T. (2011). Student and teacher self-efficacy and the connection to reading and writing. Canadian Journal of Education, 34(1), 65-98.

Fast, L. A., Lewis, J. L., Bryant, M. J., Bocian, K. A., \& Cardullo, R. A. (2010). Does math self-efficacy mediate the effect of the perceived classroom environment on standardized math test performance? Journal of Educational Psychology, 102(3), 729-740. http://dx.doi.org/10.1037/a0018863

Geary, D. C. (2004). Mathematical and learning disabilities. Journal of Learning Disabilities, 37, 4-15. http://dx.doi.org/10.1177/00222194040370010201

Glaser, B., \& Strauss, A. L. (1967). The discovery of grounded theory: Strategies for qualitative research. Chicago: Aldine.

Guba E. G., \& Lincoln Y. S. (2005). Paradigmatic, controversies, contradictions, and emerging confluences. In N. K. Denzin \& Y. S. Lincoln (Eds.), The Sage Handbook of Qualitative Research. ( ${ }^{\text {rd }}$ edition). London: Sage Publications, 191- 215.

Hoy, A.W., \& Spero, R. B. (2005). Changes in teacher efficacy during the early years of teaching: A comparison of four measures. Teaching and Teacher Education, 21, 343-356. http://dx.doi.org/10.1016/j.tate.2005.01.007

Janesick, V. J. (1994). The dance of qualitative research design: Metaphor, methodology and meaning. In N. K. Denzin \& Y. S. Lincoln (Eds.), Handbook of qualitative research. California: Sage publications, 199-208.

Katz, S. (2013). Self-efficacy - Diagnosis and Intervention: Eliciting self-efficacy beliefs through qualitative methodology. Haifa: Shaanan Publishing.

Klassen, B. (2002). A question of calibration: A review of the self-efficacy beliefs of students with learning disabilities. Learning Disability Quarterly, 25, 88-102. http://dx.doi.org/10.2307/1511276

Krasanti, R., \& Harkavi, A. (2003). Learning and thinking characteristics of "weak" students in mathematics- a summative report. Science Department. Rehovot: The Weizman Institute of Science.

Maier, S. R., \& Curtin, P. A. (2005). Self-efficacy theory: A prescriptive model for teaching research methods. Journalism and Mass Communication Educator, 59(4).

Pajares (2002). Self efficacy beliefs in academic contexts: An outline. Retrieved from http://des.emory.edu/mfp/effalk.html

Pajares, F. (2005). Self-Efficacy during childhood and adolescence self-efficacy beliefs of adolescents. Information Age, 339-367.

Pajares, F., \& Graham, L. (1999). Self-efficacy, motivation constructs, and mathematics performance of entering middle school students. Contemporary Educational Psychology, 24, 124-139. http://dx.doi.org/10.1006/ceps.1998.0991

Pintrich, P. R., \& DeGroot, E.V. (1990). Motivational and self regulated learning components of classroom academic performance. Journal of Educational Psychology, 82, 33-40. http://dx.doi.org/10.1037/0022-0663.82.1.33

Schunk, D. H., \& Zimmerman, B. (2006). Competence and control beliefs: Distinguishing the means and ends. In P.A. Alexander \& P.H. Winne (Eds.), Handbook of Educational Psychology (pp. 349-367). Mahwah, NJ: Lawrence Erlbaum Associates, Inc.

Schunk, D. H., \& Zimmerman, B. J. (2007). Influencing children self-efficacy and self-regulation of reading and writing through modeling. Reading and Writing Quarterly, 23, 7-25. http://dx.doi.org/10.1080/10573560600837578

Stake R. E. (2010). Qualitative Research: Studying how Things Work. NY, London: The Guilford Press. 
Tait-McCutcheon, S. L. (2008). Self-efficacy in mathematics: Affective, cognitive, and conative domains of functioning. From Proceedings of the $31^{\text {st }}$. Annual Conference of the Mathematics Education Research Group of Australia.

Tedick, D. J. (2006). Proficiency-Oriented language instruction and assessment: Standards, Philosophies, and Considerations for Assessment. Minneapolis, MN: University of Minnesota. Retrieved from http://www.carla.umn.edu/articulation/polia/pdf_files/standards.pdf

Zeldin, A. L., \& Pajares, F. (2000). Against the odds: Self-efficacy beliefs of women in mathematical, science \& technological careers. American Educational Research Journal, 37, 215-246. http://dx.doi.org/10.3102/00028312037001215

Zimmerman, B. J. (1995). Self regulation involves more than meta-cognition: A social cognitive perspective. Educational Psychologist, 30(4), 217-221. http://dx.doi.org/10.1207/s15326985ep3004_8

Zimmerman, B. J. (2000). Attaining self-regulation: A social cognitive perspective. In: M. Boekaerts, P. R. Pintrich., \& M. Zeidner (Eds.). Handbook of Self-Regulation (Chapt, 2. pp. 13-41). San Giego. CA: Academic Press.

Zimmerman, B.J., Bonner, S., \& Kovach, R. (1996). Developing Self Regulated Learners. American Psychological Association. Washington D.C. http://dx.doi.org/10.1037/10213-000 